\title{
Flowing biofilms as a transport mechanism for biomass through porous media under laminar and turbulent conditions in a laboratory reactor system
}

\author{
P. Stoodley , I. Dodds , D. De Beer , H. Lappin Scott \& J. D. Boyle
}

To cite this article: P. Stoodley , I. Dodds , D. De Beer , H. Lappin Scott \& J. D. Boyle (2005) Flowing biofilms as a transport mechanism for biomass through porous media under laminar and turbulent conditions in a laboratory reactor system, Biofouling, 21:3-4, 161-168, DOI: $10.1080 / 08927010500375524$

To link to this article: https://doi.org/10.1080/08927010500375524

册Published online: 25 Jan 2007.

Submit your article to this journal 20

山ll Article views: 240

Q View related articles $\sqsubset$

Citing articles: 28 View citing articles $\longleftarrow$ 


\title{
Flowing biofilms as a transport mechanism for biomass through porous media under laminar and turbulent conditions in a laboratory reactor system
}

\author{
P. STOODLEY ${ }^{1}$, I. DODDS ${ }^{2}$, D. DE BEER ${ }^{3}$, H. LAPPIN SCOTT ${ }^{1} \&$ J. D. BOYLE ${ }^{2}$ \\ ${ }^{1}$ School of Biological Sciences, University of Exeter, Devon, UK, ${ }^{2}$ School of Engineering, Mathematics and Computer Sciences, \\ Harrison Building, New North Road, University of Exeter, Devon, UK, and ${ }^{3}$ Max Planck Institute for Marine Microbiology, \\ Bremen, Germany
}

(Received 11 fuly 2005; accepted 20 September 2005)

\begin{abstract}
Fluid flow has been shown to be important in influencing biofilm morphology and causing biofilms to flow over surfaces in flow cell experiments. However, it is not known whether similar effects may occur in porous media. Generally, it is assumed that the primary transport mechanism for biomass in porous media is through convection, as suspended particulates (cells and flocs) carried by fluid flowing through the interstices. However, the flow of biofilms over the surfaces of soils and sediment particles, may represent an important flux of biomass, and subsequently affect both biological activity and permeability. Mixed species bacterial biofilms were grown in glass flow cells packed with $1 \mathrm{~mm}$ diameter glass beads, under laminar or turbulent flow (porous media Reynolds number $=20$ and 200 respectively). The morphology and dynamic behavior reflected those of biofilms grown in the open flow cells. The laminar biofilm was relatively uniform and after $23 \mathrm{~d}$ had inundated the majority of the pore spaces. Under turbulent flow the biofilm accumulated primarily in protected regions at contact points between the beads and formed streamers that trailed from the leeward face. Both biofilms caused a 2 to 3 -fold increase in friction factor and in both cases there were sudden reductions in friction factor followed by rapid recovery, suggesting periodic sloughing and regrowth events. Time-lapse microscopy revealed that under both laminar and turbulent conditions biofilms flowed over the surface of the porous media. In some instances ripple structures formed. The velocity of biofilm flow was on the order of $10 \mu \mathrm{m} \mathrm{h}^{-1}$ in the turbulent flow cell and $1.0 \mu \mathrm{m} \mathrm{h}^{-1}$ in the laminar flow cell.
\end{abstract}

Keywords: Biofilm, flow, friction factor, hydrodynamics, porous media, morphology

\section{Introduction}

The flow regime has been shown to be an important factor in biofilm development both in terms of community and structure (Purevdorj et al. 2002; Battin et al. 2003; Rickard et al. 2004). In closed channel flow cells it was found that biofilms grown under high shear turbulent flow $\left(5.1 \mathrm{~N} \mathrm{~m}^{-2}\right)$ with glucose as the sole carbon source $(40 \mathrm{ppm})$ formed viscoelastic filamentous "streamers" and traveling ripple structures which were thought to contribute to the high pressure drops associated with these types of biofilms in industrial pipelines (Stoodley et al. 1998; 1999a; 1999b). Under low shear laminar flow the biofilms were markedly different and consisted of hemispherical mounds surrounded by a monolayer of cells. The discovery that biofilms could flow over surfaces also led to the hypothesis that this mechanism may contribute to the spread of biofilms in various industrial and medical fluid bearing pipes, particularly since the cells are presumably in the protected antimicrobial biofilm resistant state. However, the activity and hydrodynamics of biofilms growing in porous media are also relevant to many industrial and environmental processes (Bouwer et al. 2000). This interest has inspired the development of a number of mathematical models to describe biofilm growth and hydrodynamic interactions in porous media (Taylor \& Jaffe, 1990; Rittman, 1993; Jennings et al. 1995; Wanner et al. 1995; Dodds, 1999). These models must make certain assumptions concerning the effect of fluid shear on biofilm morphology and development.

However, data concerning the microstructure of biofilms grown in porous media under different hydrodynamic conditions are scarce, since microscopic observation is hampered by the difficulty of observing biofilm growth inside the media. Paulsen 
et al. (1997) used an artificially generated rock core and a mixed population of seawater bacteria. By taking images at several points to record changes in biofilm morphology, they observed what they termed a "bioweb" of biofilm in many of the pore spaces.

They also found that the pores, which showed the greatest permeability, blocked first, causing diversion of flow to less permeable areas. Flow rate was held constant at $0.01 \mathrm{ml} \mathrm{min}^{-1}$ (porous media Reynolds number $\left.\left(\operatorname{Re}_{p m}\right) \approx 0.1\right)$ and the glucose concentration was $10 \mathrm{mg} \mathrm{l}^{-1}$. Cunningham et al. (1991) used glass beads inoculated with $P$. aeruginosa under a constant head and laminar flow arrangement. After $3 \mathrm{~d}$, biomass growth was uniform but after $5 \mathrm{~d}$ biofilm had accumulated in pockets on the downstream side of the contact point between neighbouring beads (Cunningham et al. 1990; 1991). A similar experiment was conducted by Wanner et al. (1995) using a constant flow rate of $38 \mathrm{ml} \mathrm{min}{ }^{-1}\left(\operatorname{Re}_{p m}=70\right)$ and a glucose concentration of 7-12 $\mathrm{mg}^{-1}$. They modeled the data using the simulation program AQUASIM (http://www.aquasim.eawag.ch/) and concluded that the biofilm did not grow evenly on the glass bead but preferentially filled "dead zones" in the pore spaces. They hypothesized that the radii of any channels in the porous media will either be significantly reduced in radius or completely plugged by biofilm growth. More recently Sharp et al. (2005) used a naturally bioluminescent biofilm grown from $V$. fischeri, and nigrosin as a dye tracer, to determine the effect of biofilm growth and activity on channeling in a flat plate model system. They found that as the biofilm developed the flow regime changed from plug flow to channeled flow and that the channel pattern switched dramatically when a particular pore became blocked by biofilm.

In previous work, the present authors used a closed channel flow cell system to compare the structure and dynamic behavior (flow of biofilms over surfaces) grown under laminar and turbulent flow (Stoodley et al. 1999a). It was the goal of the present study to extend this model to a porous media situation by packing the flow cells with glass beads and non-destructively correlating the growth and behavior of biofilm using digital imaging microscopy and pressure drop monitoring.

\section{Materials and methods}

\section{Biofilm reactor system}

The reactor system consisted of two square glass flow cells ( $3 \mathrm{~mm}$ wide, $3 \mathrm{~mm}$ deep, and $200 \mathrm{~mm}$ long, S-103 Camlab Ltd, Cambridge, UK.) (FC 1 and FC2) which were incorporated into a recycle loop fed from a mixing chamber as previously described (Stoodley et al. 1999a) (see Figure 1).

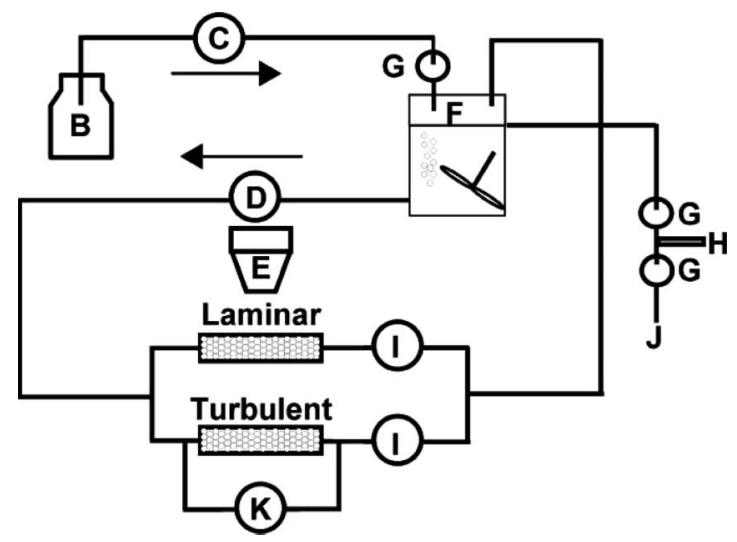

Figure 1. Biofilm reactor system consisting of the laminar and turbulent flow cells positioned in a recycle loop, with nutrients (B), peristaltic pump (C), vane head pump (D), microscope objective $(E)$, aerated mixing chamber $(F)$, flow breaks $(G)$, sampling port $(\mathrm{H})$, flow meter $(\mathrm{I})$, effluent line $(\mathrm{J})$, and pressure drop meter $(\mathrm{K})$.

The flow cells were packed tightly with $1 \mathrm{~mm}$ diameter glass beads and held in place by a coarse plastic gauze at each end. Nutrients were delivered by peristaltic pump (Masterflex, Cole Parmer, Niles, IL, USA) and the recycle flow rate was controlled with a vane head pump (Masterflex, Cole Parmer, Niles, IL, USA). The nutrient influent flow rate $\left(\mathrm{Q}_{\mathrm{n}}\right)$ was $4.3 \mathrm{ml} \mathrm{min}^{-1}$ giving a resulting residence time in the entire reactor system $\left(\mathrm{q}=\mathrm{V} / \mathrm{Q}_{\mathrm{n}}\right)$ of approximately $40 \mathrm{~min}$ (Stoodley et al. 1999a). The flow rate and hence the average flow velocity $(\mathrm{u})$ through each flow cell was controlled using a clamp and measured using a flow meter (McMillan Flo-sensor model 101T \# 3724 supplied by Cole-Parmer, Niles, IL). The pressure drop $(\Delta \mathrm{P})$ across each $\mathrm{FC}$ was measured using a differential pressure transducer (RS Components, Corby, Northants, UK, model $286-686$ ). The distance between pressure ports was $24 \mathrm{~cm}$. The pressure transducer was calibrated using a water manometer. Two experimental runs (Run 1 and Run 2) were performed in which biofilms were grown for 23 and $24 \mathrm{~d}$. The flow cells were positioned on a polycarbonate holder, which was mounted on the microscope stage so that the biofilm could be imaged without interrupting flow. Under operating conditions, the water temperature in the reactor system was $28^{\circ} \mathrm{C}$.

\section{Inoculum}

Four Gram-negative species, Pseudomonas aeruginosa (ATTC 700829), P. fluorescens (ATTC 700830), Klebsiella pneumoniae (ATTC 700831) and Stenotrophomonas maltophilia (a laboratory isolate described in Stoodley et al. 2001), which are commonly isolated from environmental and industrial biofilms, were used to inoculate the reactor (Stoodley et al. 
1999a). Each of the four species could be identified and enumerated by serial plating on King's B agar with added brom-thymol blue (BTB, $0.03 \mathrm{gl}^{-1}$ ) as a $\mathrm{pH}$ indicator. The reactor was initially run as a recirculating batch culture for $24 \mathrm{~h}$, to allow bacteria to attach to the flow cells, before switching to continuous culture with constant feed and effluent flows. Although not measured in this experiment, the authors had previously found that the mature biofilm was dominated by $K$. pneumoniae $(\sim 89 \%)$ followed by $P$. aeruginosa $(\sim 7 \%), P$. fluorescens $(\sim 2 \%)$ and S. maltophilia $(\sim 2 \%)$ (Stoodley et al. 2001).

\section{Nutrients}

The growth medium was a minimal salts medium (potassium phosphate monobasic $\left(\mathrm{KH}_{2} \mathrm{PO}_{4}\right) 70 \mathrm{mg} \mathrm{l}^{-1}$, potassium phosphate dibasic $\left(\mathrm{K}_{2} \mathrm{HPO}_{4}\right) 30 \mathrm{mg}^{-1}$, ammonium sulphate $\left(\left(\mathrm{NH}_{4}\right)_{2} \mathrm{SO}_{4}\right) 10 \mathrm{mg}^{-1}$, magnesium sulphate $\left.\left(\mathrm{MgSO}_{4} 7 \mathrm{H}_{2} \mathrm{O}\right) 10 \mathrm{mg} \mathrm{l}^{-1}\right)$ with glucose $\left(40 \mathrm{mg} \mathrm{l}^{-1}\right.$ ) as the carbon source and trace elements (mg $1^{-1}$ ): $\mathrm{Na}_{2}$ EDTA. $2 \mathrm{H}_{2} \mathrm{O}, 12 ; \mathrm{FeSO}_{4} .7 \mathrm{H}_{2} \mathrm{O}, 2$; $\mathrm{CaCl}_{2}, 1 ; \mathrm{Na}_{2} \mathrm{SO}_{4}, 1, \mathrm{ZnSO}_{4} \cdot 7 \mathrm{H}_{2} \mathrm{O}, 4 ; \mathrm{MnSO}_{4} \cdot 4 \mathrm{H}_{2} \mathrm{O}$, 4; $\mathrm{CuSO}_{4} \cdot 5 \mathrm{H}_{2} \mathrm{O}, 1 ; \mathrm{Na}_{2} \mathrm{MoO}_{4} \cdot 2 \mathrm{H}_{2} 0,1$. After autoclaving, the $\mathrm{pH}$ of the medium was 6.8 .

\section{Microscopy and image analysis}

The biofilms were observed using an Olympus BH2 upright microscope with epifluorescence capabilities. Reflected illumination was used for routine monitoring of the biofilm, with two fibre optic light sources providing overhead illumination. Low power magnification $(4 \times$ and $10 \times$ objectives $)$ was used to observe the macrostructure of the biofilm and allow a large depth of field for observing biofilm in the voids deep in the flow cell (up to approximately $1,000 \mu \mathrm{m})$. Under these microscopic conditions single bacterial cells could not be resolved. A COHU 4612-5000 CCD camera (Cohu, Inc., San Diego, CA, USA) and a Scion VG-5 PCI framestore board (Scion Inc. Frederick, MD, USA) were used to capture images (Stoodley et al. 1999a). Image processing and analysis (to measure lengths associated with biofilm morphology such as thickness and distance traveled at different time points) and was done on a Macintosh 7200/90 computer using the public domain NIH-Image 1.59 program (developed at the National Institutes of Health and available from the Internet by anonymous FTP from zippy.nimh.nih.gov or a floppy disk from the National Technical information service, Springfield, Virginia, USA, part number PB95-500195GEI). A $1 \mathrm{~mm}$ graticule with $10 \mathrm{~mm}$ divisions (Ref. \# CS990, Graticules Ltd, Tonbridge, Kent, UK) was used for calibration.

\section{Flow cell hydrodynamics}

To determine the hydrodynamic characteristics of the clean flow cells friction-factor charts were constructed by calculating the porous media friction factor $\left(f_{p m}\right)$ from the measured pressure drop over a range of porous media Reynolds number $\left(\operatorname{Re}_{p m}\right)$. $\mathrm{Re}_{p m}$ can be stated as:

$$
\operatorname{Re}_{p m}=\frac{u d}{v}
$$

where $u$ is the specific discharge velocity defined as the flow rate divided by the total cross sectional area of the reactor, $d$ is the mean diameter of the porous media, and $v$ is the fluid kinematic viscosity for water $\left(0.84 \times 10^{-6} \mathrm{~m}^{2} \mathrm{~s}^{-1}\right)$. The porous medium friction factor $f_{p m}$ was found from Carman (1937):

$$
f_{p m}=\frac{\Delta H d n^{3} g}{L(1-n) u^{2}} f_{w}
$$

where $\Delta H$ is the pressure loss across the porous media, $d$ is the diameter of the glass beads, $L$ is the length of the porous media bed, $n$ is the porosity and $u$ is the fluid velocity. The $f_{w}$ is a correction factor to allow for wall effects, necessary since the beads were large compared with the channel width and packing at the edge will be less compact than at the center and has been experimentally determined by Coulson (1949):

$$
f_{w}=\left(1+\frac{1}{2} \frac{M_{c}}{M}\right)^{2}
$$

where $M_{c}$ is the surface of the cell per unit volume of media and $M$ is the specific surface area of the beads which for a sphere is $6 / \mathrm{d}$. The friction factor chart of clean flow cells was used to define the laminar and turbulent zones (see Figure 3) as well as to provide a negative control with which to compare after biofilm colonization. From the change in the gradient the transition between laminar and turbulent flow was determined as occurring at approximately $\operatorname{Re}_{p m} 40$. This corresponds well with Carman (1937) who reported the transition zone in the $\mathrm{Re}_{p m}$ 5-50 range and Coulson and Richardson (1996) who report a transition range of $10-30$. Based on the friction factor data $\mathrm{Re}_{p m}$ of 20 and 200 were chosen to represent the "laminar" and "turbulent" flow conditions respectively. To achieve these $\mathrm{Re}_{p m}$ fluid velocity in the laminar and turbulent flow cells were maintained at 0.02 and $0.2 \mathrm{~ms}^{-1}$ respectively during the growth phase. For Run 1 after the 23-d growth period friction-factor charts were constructed again to compare the clean flow cells with the biofilm colonized flow cells. The $\mathrm{Re}_{p m}$ in both flow cells was reduced to approximately 10 and the $f_{p m}$ measured at incrementally increasing $\mathrm{R}_{p m}$. The biofilm grown at 
$\operatorname{Re}_{p m} 20$ sloughed when the $\operatorname{Re}_{p m}$ was elevated to 30 so no further data were available for this flow cell.

\section{Hydraulic resistance}

At the end of Run 1 (day 23), pressure transducers were inserted into two bypass pipes and the pressure loss across each of the laminar and turbulent flow cells was recorded at incremental flow rates. The test was stopped at the maximum non-destructive flow rate which was determined as the point of the onset of biofilm detachment. In Run 2 the pressure loss was measured throughout the experiment.

\section{Biofilm flow}

To measure the flow of biofilm over the surface of the glass beads sterile neutral density fluorescent latex spheres (Molecular Probes, Eugene Oregon, diameter $=0.282 \mu \mathrm{m}$ ) were stuck to the biofilm as fiducial points as previously described (Stoodley et al. 1999b). The spheres were added to the reactor via the mixing chamber to achieve a final concentration of about $1 \times 10^{7}$ spheres $\mathrm{ml}^{-1}$. The distance traveled was measured using time-lapse monitoring using epifluorescence and light microscopy. Linear velocities were found from linear regression of the distance-time data. These were used to calculate mean velocities and standard deviation.

\section{Results}

\section{Biofilm morphology}

Biofilms were observed growing in the pores and on the bead surfaces of both flow cells in both experimental runs (see Figure 2). However, the morphology of the biofilm in the laminar and turbulent flow cells exhibited different characteristics throughout the duration of the experiments. In the laminar flow cell, $4 \mathrm{~d}$ post inoculation; the biofilm was relatively uniform over the bead surfaces and was $10-20 \mu \mathrm{m}$ thick. By day 8 , the biofilm had increased to $20-30 \mu \mathrm{m}$ thick and by day 11 was $30-40 \mu \mathrm{m}$ thick. The biofilm remained relatively uniform with no discernible difference in thickness between the upstream and downstream sides of the glass beads. However, at several points there appeared to be some in-filling of the pore spaces, especially near the contact points of the beads and even some bridging, where the beads were close to one another. On day 11, time-lapse microscopy revealed the presence of ripple structures running perpendicular to the flow. By day 16 , the biofilm had become patchy and some streamers had developed. The streamers were anchored to an upstream bead and trailed into the downstream pore space.

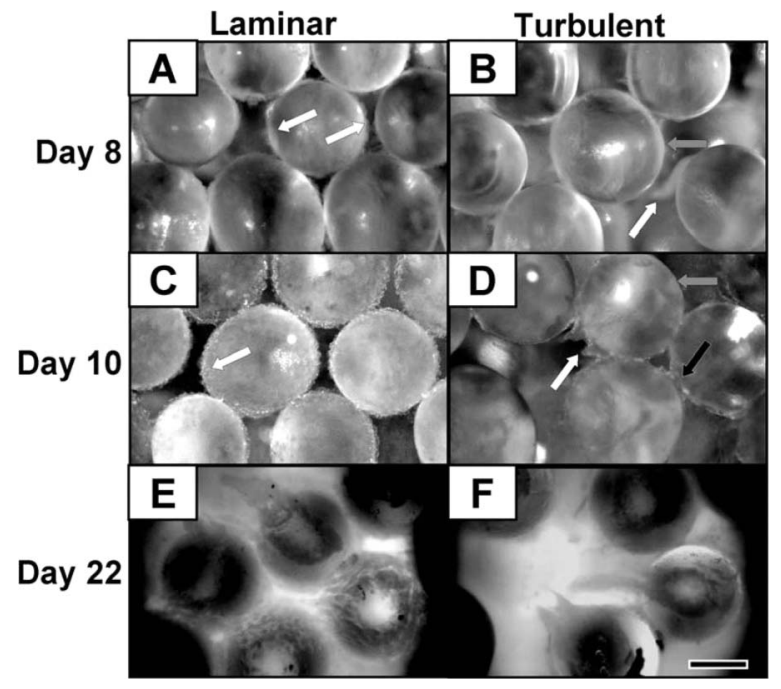

Figure 2. Biofilm growth on $1 \mathrm{~mm}$ diameter glass beads in the laminar and turbulent flow cells on days 8,10 and 22. Flow was from right to left in all panels. (A) Arrows indicate uniform biofilm around the beads grown in laminar flow. (B) In the turbulent flow cell there was less biofilm on the facing edge of the beads (grey arrow) and streamers had formed (white arrow) which trailed from the downstream face. (C) Fluorescent spheres adhered to the biofilm (white arrow) were used to enhance visualization and detect biofilm flow. (D) In the turbulent flow cell the fluorescent spheres reveal streamers (white arrow) and biofilm growth between contact points (black arrow). The facing surfaces were relatively devoid of biofilm (grey arrow). (E) By day 22 the biofilm in the laminar flow cell had also formed streamers and had inundated the pore volumes. (F) Well developed streamers in the turbulent flow cell. Scale bar $=500 \mu \mathrm{m}$ in all frames.

By day 22 the biofilm had inundated the majority of the pore spaces with either streamer formation or contiguous growth. In the turbulent flow cell, the morphology of the biofilm grown was noticeably less uniformly distributed (see Figures 2B, 2D and 2E). Four days post inoculation, the base biofilm was sparsely distributed and concentrated on the downstream face. Generally the upstream face was devoid of biofilm. The thickness of the "base" biofilm was approximately $5 \mu \mathrm{m}$. However, in some locations, streamers of between 90 and $300 \mu \mathrm{m}$ had developed, which oscillated in the pore spaces. In addition, ripples running perpendicular to the flow direction had formed on some of the beads. The ripples were approximately $60 \mu \mathrm{m}$ in width and separated by a gap of $12 \mu \mathrm{m}$. Time-lapse microscopy indicated that the ripples were stationary over a $10-\mathrm{h}$ monitoring period. After $8 \mathrm{~d}$, unlike the laminar flow cell, the biofilm exhibited much greater heterogeneity. In protected areas, and on the downstream side of the beads, the biofilm was approximately $25-35 \mu \mathrm{m}$ thick, while the upstream faced generally remained clear of biofilm. By day 22 the streamers had elongated and trailed into the pore spaces. Biofilm was apparent on the upstream side of the beads, but generally thinner than on the downstream side. 


\section{Head loss with biofilm growth}

On day 23 of Run 1, a friction factor chart was constructed for the biofilm colonised flow cells (see Figure 3). The growth of both biofilms resulted in an increase in $f_{p m}$ by a factor of approximately 2 , but there was little difference between the laminar and turbulent grown biofilms. However, the laminar grown biofilm detached at $\operatorname{Re}_{p m}=30$ limiting the testing range. The laminar grown biofilm exhibited less resistance than the turbulent biofilm even though microscopy indicated a greater accumulation of biomass. In Run 2 the head loss was monitored throughout the experiment (see Figure 4). The initial and final $f_{p m}$ were similar to those in Run 1 (Figure 3).

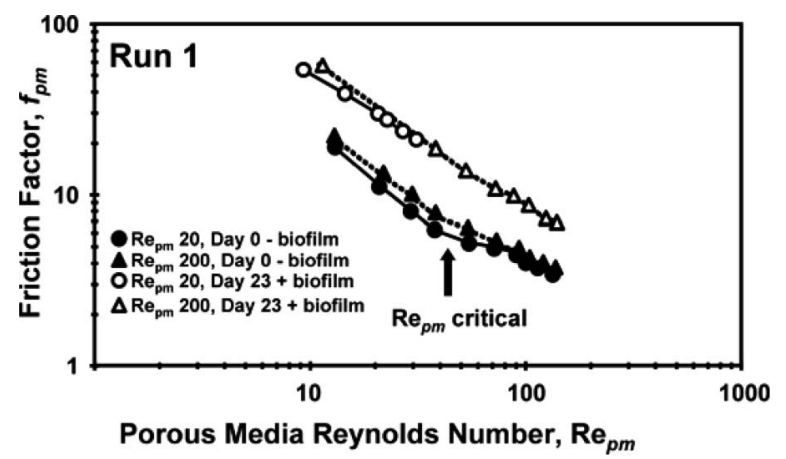

Figure 3. Porous media friction factor $\left(f_{p m}\right)$ chart for clean (closed symbols) and biofilm colonised flow cells (open symbols) from Run 1. The critical $\mathrm{Re}_{p m}$ was approximately 40 (black arrow). During the 23 day growth phase the $\mathrm{Re}_{p m}$ was kept at 20 for the laminar flow cell and 200 for the turbulent flow cell. At the end of the 23 day growth period the $\mathrm{Re}_{p m}$ in both flow cells was reduced to approximately 10 and the $f_{p m}$ measured at incrementally increasing $\mathrm{R}_{p m}$ to construct friction factor charts to allow cells before and after in the flow biofilm colonisation comparisons of the $\mathrm{Re}_{p m}-f_{p m}$ relationship. The biofilm grown at $\mathrm{Re}_{p m} 20$ (o) sloughed when the $\operatorname{Re}_{p m}$ was elevated to 30 so no further data were available.

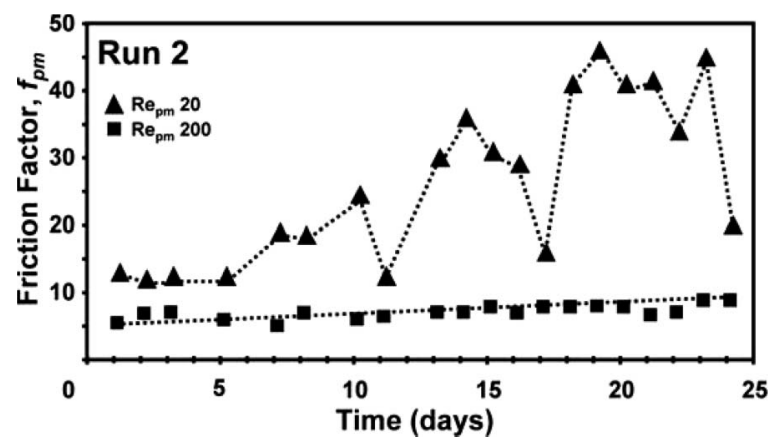

Figure 4. Friction factor with time for laminar and turbulent grown biofilms. In the laminar flow cell there were three substantial drops in $f_{p m}$ on days 11,17 and 24 , followed by rapid recovery. Similar drops may have occurred in the turbulent flow cell on days 16 and 21 but were less discernable on this scale due to the reduced sensitivity of the measurement at the higher flow rate.
Because the $f_{p m}$ values were measured at $\mathrm{Re}_{p m}=20$ and 200 for the laminar and turbulent flow cells respectively, and $f_{p m}$ was inversely related to $\mathrm{Re}_{p m}$ over this range (Figure 3), the curves can be used to monitor the effects of biofilm colonisation over time but are not directly comparable. The laminar flow cell showed an increasing trend in $f_{p m}$ over the duration of the experiment from $\approx 13$ to $\approx 46$. Three sudden drops in $f_{p m}$ were measured. These drops occurred on days 11, 17 and 24, suggesting a possible periodicity of approximately $6 \mathrm{~d}$. The $f_{p m}$ rapidly recovered, returning to the overall pattern over the following 1 or $2 \mathrm{~d}$. The turbulent flow cell exhibited lower and more consistent values of friction factor over the duration of the experiment. Although less pronounced on this scale, there also appeared to be periodic reductions of $f_{p m}$ on days $7,16,21$ and perhaps on day 10 , suggesting a possible periodicity of between 3 and 6 d. Post-experimental examination of the record of microscopic images did not identify any notable changes, such as detachment and rapid regrowth, to biofilm structure around these times. The time-lapse sequences did not coincide with these events, and if they occurred rapidly, or overnight, they may have been missed.

\section{Biofilm movement}

Time-lapse movies taken between days 4 and 16 showed the biofilm flowing around beads in both laminar and turbulent biofilms. Biofilm movement was more evident in the turbulent flow cell. As biofilm flowed around the sides of beads it "pooled" on the leeward face, from where it streamed into the pore space. In some cases the biofilm exhibited necking and ultimately produced "drops" of biofilm which detached into the bulk fluid flow. Fluorescent microspheres attached to the biofilm were used as fiducial points to measure biofilm movement on day 11 in the laminar flow cell and 16 in the turbulent flow cell. On day 16 the biofilm flow velocity in the turbulent flow cell was $5.8 \pm 2.1 \mu \mathrm{m} \mathrm{h}^{-1}(n=6)$ (see Figure 5). Regression analysis of mean distances for each time point combined gave a velocity of $6.06 \mu \mathrm{m} \mathrm{h}^{-1}$ with a standard error coefficient of 0.21 and an $\mathrm{r}^{2}$ of $0.94(n=6)$. On day 11 in the laminar flow cell the velocity of traveling ripples in the biofilm was $0.79 \mu \mathrm{m} \mathrm{h}^{-1}$ with a standard error coefficient of 0.03 and an $\mathrm{r}^{2}$ of $0.99(n=5)$ (see Figure 6).

\section{Discussion}

\section{Biofilm morphology}

By adapting a biofilm flow cell system that had previously been used to investigate the influence of 


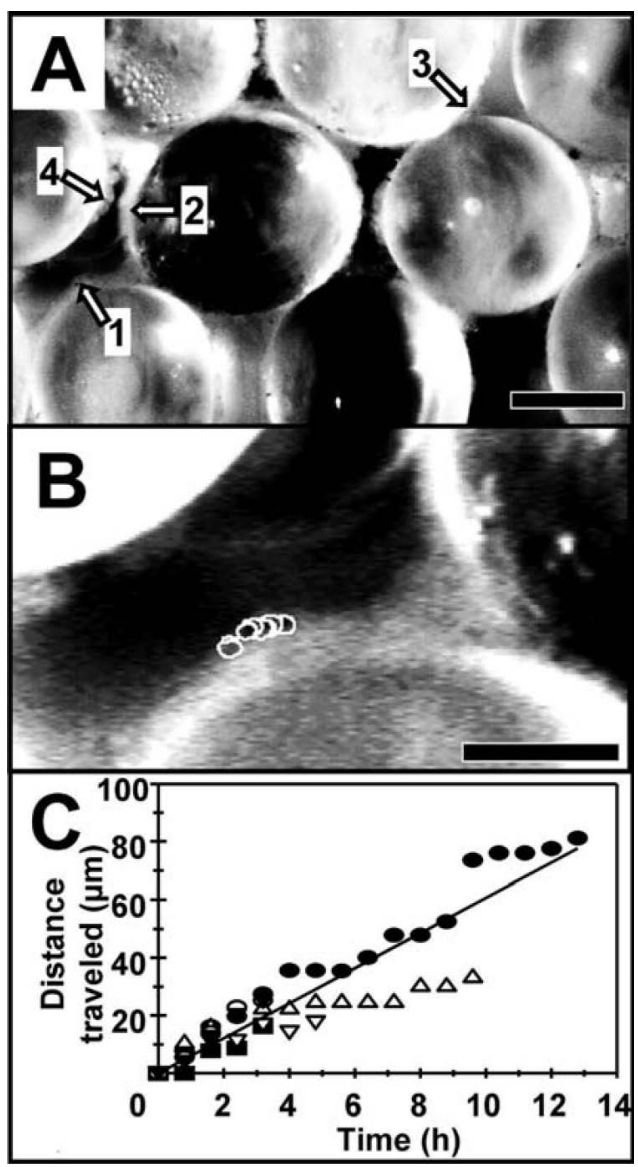

Figure 5. Time-lapse movie demonstrating biofilm flow around the bead surfaces in the turbulent flow cell on day 16. A=low magnification image showing the location of four areas of biofilm that were tracked over time. Scale bar $=500 \mu \mathrm{m}$. $\mathrm{B}=$ high magnification of the area of bead " 1 " in panel " $A$ " showing the location of a fluorescent sphere trapped in the biofilm at $96 \mathrm{~min}$ intervals over a $11.6 \mathrm{~h}$ monitoring period. Scale bar $=200 \mu \mathrm{m}$. $\mathrm{C}=$ graphed motion of six spheres beads around the bead surface. The solid line is the linear regression from the average data at each time point. The mean linear velocity was $6.1 \mu \mathrm{m} \mathrm{h}^{-1}, \mathrm{r}^{2}=0.94$.

hydrodynamics on biofilm growing in closed channels, the authors were able to extend their investigations to porous media. The morphology of the laminar biofilm in the early stages of growth was continuous and of approximately constant thickness. This can be explained by the dominating effects of substrate diffusion over the negligible effect of shear stress. With time, the biofilm thickness increased until inundation of the pores occurred. The crosssectional area of the open pores contracts until growth is balanced by the erosion due to the increased shear stress. Ultimately, this leads to the maintenance of a few open channels through which the bulk water flowed. The data are similar to those of Wanner et al. (1995). The structure of biofilm in the turbulent flow cell indicated that shear stress had a more significant role. Although after approximately

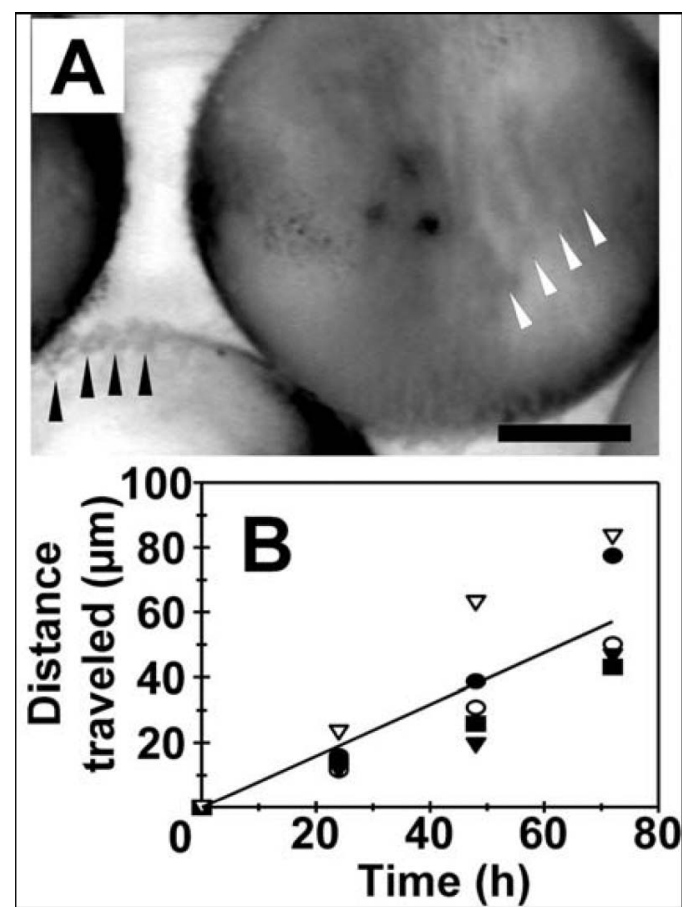

Figure 6. Flow of biofilm ripples in the laminar flow cell on Day 11. $\mathrm{A}=$ low magnification image showing two ripple patches. Black or white arrows indicate individual ripples in each patch. Scale bar $=250 \mu \mathrm{m}$. B = graphed motion of five spheres beads around the bead surface. The solid line is the linear regression from the average data at each time point. The mean linear velocity was $0.8 \mu \mathrm{m} \mathrm{h}^{-1}, \mathrm{r}^{2}=0.99(n=5)$.

$20 \mathrm{~d}$ growth was observed on most of the bead surfaces, the greatest amount of growth occurred in the protected areas on the downstream side of the beads and at the contact points between beads. The presence of streamers and moving biofilms were also suggestive of a high shear environment. There was considerable analogy regarding the influence of hydrodynamics and biofilm development and behavior between biofilms grown in porous media in the present study and biofilms grown in closed channels (Stoodley et al. 1999a; 1999b).

\section{Hydrodynamics}

As expected, the presence of biofilm had a significant effect on pressure loss across the porous media. At low Re there was a $2-3$ times increase in the $f_{p m}$ but when $\mathrm{Re}_{p m}$ was increased to 30 the laminar biofilm visibly detached, while the turbulent biofilm showed an increase of 1.6 times the original resistance. The observations are consistent with open channel experiments in which biofilms grown at higher shear stress are generally stronger and more firmly adhered than those grown at lower flows (Stoodley et al. 2002). Surprisingly, the $f_{p m}$ due to biofilm growth was similar in the laminar and turbulent flow cells 
even though there were notable differences in morphology. A possible explanation for this is that lower contribution of skin drag due to sparser coverage in the turbulent flow cell was offset by the increased drag of biofilm streamers (Picologlou et al. 1980; Stoodley et al. 1998). The $f_{p m}$ was recorded over time in Run 2. As expected there was a trend of increasing $f_{p m}$ with time due to biofilm growth. Periodic reductions of $f_{p m}$ were clear from the laminar flow cell data (Figure 5-the scaling of $f_{p m}$ measured under higher flow results in reduced resolution so the discussion will concentrate on the laminar data). It was hypothesised that these reductions in $f_{p m}$ were due to sloughing events, however, it was not possible to confirm this microscopically. Similar periodicity (approximately $6 \mathrm{~d}$ ) and patterns of detachment and regrowth were reported by Horn et al. (2003), over a 45-d growth period. As the biofilm inundates the pore spaces and blocks nutrient channels, the biofilm will rapidly become starved. This could lead to endogenous respiration and thus a weakening of the matrix (Allison, 2003) fixing the biofilm to the substratum, which precipitates a sloughing event. Nutrient related detachment has been reported for both feast (Sauer et al. 2004) and famine conditions (Gjermansen et al. 2005). The $f_{p m}$ quickly recovered following the drop rapid regrowth suggesting that the remaining biofilm rapidly utilised the fresh supply of nutrients provided by the opening up of channels. The redirecting of channels due to biofilm blocking and the subsequent initiation of new active sites has been directly observed in an in vitro porous media model (Sharp et al. 2005).

\section{Biofilm flow}

The finding that whole biofilms can flow over porous media surfaces raises interesting questions concerning the role of this mechanism as a means of biomass transport in natural environmental systems, such as marine and river sediments, as well industrial systems, such as filter beds, where it may contribute to reduced breakthrough times. The biofilm flow velocity was approximately an order of magnitude greater in the turbulent flow cell than in the laminar flow cell. The dependence of biofilm flow velocity on the fluid velocity of the bulk liquid has been demonstrated in channel flow cells (Purevdorj et al. 2002; Stoodley et al. 1999b). The present observations are consistent with the finding that biofilms can behave mechanically as viscoelastic fluids (Towler et al. 2003). Conventionally, the transport of biomass is considered to be as a suspension in the liquid phase. The flow of biofilms through porous media may be an important consideration in plugging and for the redistribution of growing biomass.
In an industrial context this may be an important consideration in oil reservoir microbiology, in which reservoir plugging through the introduction of bacteria and nutrients during pressurised waterflood may reduce recovery by unintentionally reducing permeability, or be utilised to increase productivity by means of controlled channeling (Bass \& Lappin-Scott, 1997). The flow of sulphate reducing bacteria (SRB) biofilms through porous media has been reported in an oil reservoir glass micromodel (Dunsmore et al. 2004). From an environmental perspective the present results may help explain why certain micro-organisms are sometimes found in hostile environments, outside of their favoured physiological niche. For example, SRB are commonly detected in the upper, well oxygenated, sediment and mat layers (Bühring et al. 2005), even though they generally require anoxic conditions for growth (Sigalevich et al. 2000). Finally, it is interesting to consider that the flow of biofilms through sediments may represent a significant, but unconsidered, flux of particulate organic matter (POM) and its contribution to biological activity. This may be particularly important for the transport of organic phosphorous and nitrogen, which are often limiting in oligotrophic marine sediment environments.

\section{Acknowledgments}

We are grateful for funding from the University of Exeter and a Fellowship Award to PS from the Hanse Institute for Advanced Study (HWK), Delmenhorst, Germany.

\section{References}

Allison GD. 2003. The biofilm matrix. Biofouling 19:139-150.

Bass CJ, Lappin-Scott HM. 1997. The bad guys and the good guys in petroleum microbiology. Oilfield Rev 9:17-25.

Battin TJ, Kaplan LA, Newbold JD, Cheng X, Hansen C. 2003. Effects of current velocity on the nascent architecture of stream microbial biofilms. Appl Environ Microbiol 69: $5443-5452$.

Bouwer EJ, Rijnaarts HHM, Cunningham AB, Gerlach R. 2000. Biofilms in porous media. In: Bryers J, editor. Biofilms II: process analysis and applications. New York: Wiley-Liss, Inc. pp 123-158.

Bühring SI, Elvert M, Witte U. 2005. The microbial community structure of different permeable sandy sediments characterized by the investigation of bacterial fatty acids and fluorescence in situ hybridization. Environm Microbiol 7:281-293.

Carman PC. 1937. Fluid flow through granular beds. Trans I Chem E 15:150-166.

Coulson JM. 1949. The flow of fluids through granular beds; effect of particle shape and voids in streamline flow. Trans I Chem E 27:237-257.

Coulson JM, Richardson JF. 1996. Chemical engineering. Vol. 2. Oxford, UK: Butterworth Heinemann.

Cunningham AB, Bouwer EJ, Characklis WG. 1990. Biofilms in porous media. In: Characklis WG, Marshall KC, editors. Biofilms. New York: John Wiley \& Sons. pp 697-732. 
Cunningham AB, Characklis WG, Abedeen F, Crawford D. 1991. Influence of biofilm accumulation on porous media hydrodynamics. Environ Sci Technol 25:1305-1310.

Dodds I. 1999. Bacterial activity in permeable beds. $\mathrm{PhD}$ thesis, University of Exeter, Exeter, UK.

Dunsmore BC, Bass CJ, Lappin-Scott HM. 2004. A novel approach to investigate biofilm accumulation and bacterial transport in porous matrices. Environ Microbiol 6:183-187.

Gjermansen M, Ragas P, Sternberg C, Molin S, Tolker-Nielsen T. 2005. Characterization of starvation-induced dispersion in Pseudomonas putida biofilms. Environ Microbiol 7:894-906.

Horn H, Reiff H, Morgenroth E. 2003. Simulation of growth and detachment in biofilm systems under defined hydrodynamic conditions. Biotechnol Bioeng 81:607-617.

Jennings DA, Petersen JN, Skeen RS, Hooker BS, Peyton BM, Johnstone DL, Yonge DR. 1995. Effects of slight variations in nutrient loadings on pore plugging in soil columns. Appl Biochem Biotechnol 51:727-734.

Paulsen JE, Oppen E, Bakke R. 1997. Biofilm morphology in porous media, a study with microscopic and image techniques. Water Sci Technol 36:1-9.

Picologlou BF, Zelver N, Characklis WG. 1980. Biofilm growth and hydraulic performance. J Hydraul Div Am Soc Civ Eng 106:733-746.

Purevdorj B, Costerton JW, Stoodley P. 2002. Influence of hydrodynamics and cell signaling on the structure and behavior of Pseudomonas aeruginosa biofilms. Appl Environ Microbiol 68:4457-4464.

Rickard AH, McBain AJ, Stead AT, Gilbert P. 2004. Shear rate moderates community diversity in freshwater biofilms. Appl Environ Microbiol 70:7426-7435.

Rittman BE. 1993. The significance of biofilms in porous media. Water Resour Res 29:2195-2202.

Sauer K, Cullen MC, Rickard AH, Zeef LA, Davies DG, Gilbert P. 2004. Characterization of nutrient-induced dispersion in Pseudomonas aeruginosa PAO1 biofilm. J Bacteriol 186: $7312-7326$.
Sharp RR, Stoodley P, Adgie M, Gerlach R, Cunningham A. 2005. Visualization and characterization of dynamic patterns of flow, growth and activity of Vibrio fischeri biofilms growing in porous media. Water Sci Technol 52:85-90.

Sigalevich P, Meshorer E, Helman Y, Cohen Y. 2000. Transition from anaerobic to aerobic growth conditions for the sulfatereducing bacterium Desulfovibrio oxyclinae results in flocculation. Appl Environ Microbiol 66:5005-5012.

Stoodley P, Lewandowski L, Boyle JD, Lappin-Scott HM. 1998. Oscillation characteristics of biofilm streamers in turbulent flowing water as related to drag and pressure drop. Biotechnol Bioeng 57:536-544.

Stoodley P, Dodds I, Boyle JD, Lappin-Scott HM. 1999a. Influence of hydrodynamics and nutrients on biofilm structure. J Appl Microbiol 85: 19S-28S.

Stoodley P, Lewandowski Z, Boyle JD, Lappin-Scott HM. 1999b. The formation of migratory ripples in a mixed species bacterial biofilm growing in turbulent flow. Environ Microbiol 1: $447-457$.

Stoodley P, Wilson S, Hall-Stoodley L, Boyle JD, Lappin-Scott HM, Costerton JW. 2001. Growth and detachment of cell clusters from mature mixed species biofilms. Appl Environ Microbiol 67:5608-5613.

Stoodley P, Cargo R, Rupp CJ, Wilson S, Klapper I. 2002. Biofilm mechanics and shear induced deformation and detachment. J Ind Microbiol Biotechnol 29:361-368.

Taylor SW, Jaffe PR. 1990. Substrate and biomass transport in a porous medium. Water Resour Res 26:2181-2194.

Towler BW, Rupp CJ, Cunningham AB, Stoodley P. 2003. Viscoelastic properties of a mixed culture biofilm from rheometer creep analysis. Biofouling 19:279-285.

Wanner O, Cunningham AB, Lundman R. 1995. Modelling biofilm accumulation and mass transport in a porous medium under high substrate loading. Biotechnol Bioeng 47:703-712. 